\title{
Reseña de: Marcia R. England, Maria Fannin y Helen Hazen (eds.). Reproductive Geographies. Bodies, Places and Politics. Oxon y New York: Routledge, 2019. 242 pp. ISBN : 978-0815386193
}

\author{
Lydia Delicado Moratalla \\ Universitat Jaume I, Castellón
}

Esta recopilación de artículos explora los nuevos paisajes generados a través de las tecnologías reproductivas. Analiza las experiencias, los lugares, las prácticas de la reproducción, la fertilidad, los partos, temáticas novedosas para el pensamiento feminista en Geografía. El viaje por los casos de estudio se realiza como un recorrido por el cuerpo, el hogar, los ámbitos locales, nacionales y globales. Como se expresa aquí, gran parte de los procesos asociados a la reproducción acontecen en una escala corporal, la cual es de absoluta relevancia en los estudios feministas: (in)fertilidad, abortos, lactancia, embarazos por encargo, extracción de óvulos para su venta en los mercados transnacionales... No solo es el cuerpo un territorio de estudio, en la obra también son destacadas las relaciones entre cuerpos y sociedades, un campo de análisis complejo y actual, al mismo tiempo que el lugar de la reproducción ocupa un interés particular.

El libro se organiza en una división de tres secciones, correspondientes a tres grandes conceptos que se manejan en el seno de la geografía feminista: los cuerpos, los lugares y la política. En la primera parte, se presentan algunos aspectos generales de la historia de la colección de embriones de Kyoto, considerada la más grande del mundo. Fannin estima que las colecciones embrionarias y de material biológico humano representan un aspecto importante para la comprensión de las geografías reproductivas que la ciencia

Los contenidos de la revista se publican bajo una licencia de Creative Commons Reconocimiento 4.0 Internacional (CC BY 4.0)

Feminismo/s 34, diciembre 2019, pp. 367-374 
contemporánea ha establecido. La formas tradicionales de recopilar estos materiales humanos, originadas en abortos espontáneos o deseados y otras causas vinculadas a enfermedades, se han visto trasformadas con la irrupción de la fertilización in vitro, dado que en cada proceso, se producen embriones en exceso, que se utilizan posteriormente en los circuitos de investigación sobre la evolución de la vida desde la concepción hasta el nacimiento. Se trata, señala la autora, de las nuevas prácticas que han aportado los avances de las tecnologías reproductivas, al mismo tiempo que se destaca la invisibilidad que han tenido las donaciones de las mujeres en materia de reproducción humana en la literatura científica.

Los mapas de genes, utilizados en los laboratorios de las clínicas de fertilidad, forman parte del proceso empleado para diagnosticar posibles anomalías en los embriones resultantes de la fertilización in vitro. Mientras se han configurado rutas trasnacionales para la movilización de óvulos, esperma, embriones y fetos, es interesante constatar cómo se han formado otras geografías en los espacios del interior de la vida: embriones, genes, tejidos. Collard destaca que estos circuitos por los que hay una hipermovilización de material genético, significan una re-espacialización de la vida: su creación ya no se produce sólo en el espacio corporal, ahora se genera en los laboratorios. Acude a las teorías de Foucault para cuestionar los criterios que se emplean en la clasificación de la normalidad o anormalidad de los embriones, pues aunque todo ello pertenece a una esfera biológica, en la dicotomía normal/ anómalo intercede lo social y lo político. Aquellos embriones considerados anómalos, aun tipificados no válidos para desarrollarse como seres humanos completos, adquieren sin embargo un valor extraordinario en los mercados de la vida, como recurso biológico del que se pueden extraer otros beneficios: en este caso, el objetivo no es la reproducción humana, sino el cultivo de material humano con potencial para la experimentación y el beneficio. Estos embriones son descartados por la industria reproductiva pero, sin embargo, suponen un recurso para las emergentes bio-industrias del siglo XXI y la creación de economías basadas en los tejidos humanos, que potencian la fragmentación de los cuerpos.

Para Marcia England, todo lo relativo a la reproducción artificial es eminentemente geográfico. Se han creado diversos espacios para la reproducción humana, que anteriormente eran inexistentes y ha habido una traslación de

Feminismo/s 34, diciembre 2019, pp. 367-374 
todo lo referente a la reproducción y a la fertilidad desde el espacio privado, desde el hogar y lo íntimo, hacia lo público. Por su parte, explora las elecciones que hacen las personas que acuden a los bancos de esperma, se centra en cómo realizan el proceso de búsqueda y la incidencia de la movilidad en este bio-mercado. Los clientes y clientas que acuden a los bancos de esperma reciben información de las características físicas y sociales de los donantes. De alguna manera, se proyectan ciertas expectativas de que el semen sea portador de los rasgos sociales, lo que, al parecer, ayuda en el proceso de selección de donante. ¿Existen características eugénicas en el mercado de esperma? Marcia England se lo pregunta y explora el estado de la cuestión, al observar ciertas expectativas raciales y de adecuación a cánones en las formas en las que se expresan los deseos de las personas que van en busca de esperma.

Mediante el uso de metodologías feministas de historia oral, observación, mapeo y fotografía participativa, el capítulo de Bhakta et al. persigue validar las experiencias y las percepciones que tienen las mujeres acerca de la menopausia, romper con su aislamiento y apostar por la elaboración de otras geografías que consideren su dimensión pública y política. Las autoras navegan por las geografías cotidianas que se configuran en el uso de agua y la higiene en relación a la menopausia y desean dar respuesta a las cuestiones de cómo los factores humanos, económicos, físicos y sociales afectan a las necesidades de higiene íntima, así como a cuáles son los aspectos espaciales y de género presentes en la perimenopausia y en qué medida la estructura patriarcal limita la movilidad de las mujeres en ese periodo. Por ello, Bhakta et al. abordan las diferencias que se aprecian en países como Nigeria, Camerún o Ghana, en las formas sociales y culturales de convivir con la menstruación y la menopausia. Por ejemplo, la comunidad Hausa de Nigeria o la Wikidum de Camerún consideran que la menopausia es una liberación para la mujer. En Ghana, el cese de la menstruación equivale a la adquisición de derechos como poder entrar en ermitas y santuarios, participar en rituales antes prohibidos o residir con diversos hombres. Aunque, al mismo tiempo, supone un estigma para las mujeres, al pensarse que pierden rasgos asociados a la feminidad y al fin último de sus vidas: procrear y ser madres. Es ese estigma, según las autoras, el causante del silenciamiento social en torno a la menopausia.

La segunda parte contiene estudios sobre el espacio de la reproducción. Las mujeres embarazadas y lactantes tienen una experiencia específica del

Feminismo/s 34, diciembre 2019, pp. 367-374 
lugar y es frecuente que se encuentren fuera de lugar en el espacio público. El estudio de caso en el capítulo de Katie Merkle nos transporta hacia los testimonios de mujeres que han vivido un embarazo siendo estudiantes universitarias. Sus vivencias indican que reciben una gran atención pública en el campus, que los comentarios de las personas alrededor son habituales. Las participantes en el estudio sienten que el campus no es un lugar que acoja los embarazos de las alumnas sin señalamiento. De sus testimonios se desprende que hay un sentimiento generalizado sobre los embarazos como no pertenecientes al contexto académico, lo que las estigmatiza intensamente.

Esta segunda parte del recopilatorio alberga, desde mi punto de vista, el capítulo más controvertido, de mano de la autora Dalia Bhattacharjee, quien propone que la gestación para otros sea conceptualizada y admitida como un trabajo. Señala que, mediante la asunción de la práctica como tal, tiene una intención explícita de querer frenar lo que denomina una conceptualización esencialista de la maternidad en el patriarcado. Las mujeres en situación de vientre de alquiler son entendidas aquí como trabajadoras eclipsadas por una narrativa dominante del victimismo. La autora defiende que los embarazos comerciales deben incorporar un significado de trabajo, con el objetivo de que las mujeres no sean sólo identificadas como subrogadas o reemplazadas. El estudio mantiene la posición de que la gestación para otros subvierte la dicotomía de género que crea líneas divisorias entre lo público y lo privado, el trabajo y aquello que no lo es.

Las aquí llamadas trabajadoras reproductivas equiparan los embarazos comerciales con un trabajo virtuoso en el que pueden ayudar a otras personas. Es frecuente en ellas la creación de una distancia con respecto a las situaciones de prostitución. Argumentan que los vientres de alquiler marcan la diferencia en que son una práctica piadosa y devocional. Se espera que sean devotas madres y al mismo tiempo, que no generen vínculos con las criaturas que gestan y dan a luz: a la mujer subrogada se le requiere que sea una trabajadora-productora y, al mismo tiempo, una madre-reproductora. Aparece aquí normalizado el uso de un concepto tan discutible como el de madre gestacional, término que segrega el significado de maternidad para crear otras nuevas descripciones que han sido generadas mediante el uso de procesos artificiales en los que ha intervenido la tecnología, la cual ha creado la innovación de incorporar el dolor intenso a la concepción de la vida.

Feminismo/s 34, diciembre 2019, pp. 367-374 
Reseña de: Marcia R. England, Maria Fannin y Helen Hazen (eds.). Reproductive Geographies. Bodies, Places and Politics. Oxon y New York: Routledge, 2019. 242 pp.

ISBN : 978-0815386193

El capítulo de Helen Hazen aborda las particularidades de los lugares de elección para parir y su dimensión política, el parto como un lugar representativo de las formas patriarcales de articular el control sobre los cuerpos y las vidas de las mujeres. Reflexiona sobre la idea de resistencia a la autoridad médica androcentrada que representan aquellas mujeres que dan a luz en lugares no hospitalizados. Habla de una corriente que defiende la necesidad de distanciamiento de aquellas prácticas médicas que identifican el embarazo y el parto como un proceso patológico. Las mujeres que defienden esta posición, afrontan sin embargo algunos retos, principalmente el cuestionamiento social que pone en duda su responsabilidad como madres, al mismo tiempo que han de manejarse con sus propios temores sobre el riesgo que asumen desafiando la conducta normalizada.

Para algunas mujeres, dar a luz en casa es un marco de empoderamiento, al sentir que pueden tener control sobre el espacio, al hacer de este una experiencia propia, personal, íntima. También consideran que la oportunidad de dar a luz en su hogar les permite estar al mando de sus cuerpos, disponiendo de autonomía y soberanía. Para Whitson, el parto en casa representa un lugar de resistencia a las normas que institucionalizan y medicalizan el proceso. El principal motivo por el que las mujeres desean dar a luz en casa es por estar en desacuerdo con el modelo intervencionista y sumamente medicalizado que para ellas se aplica en los hospitales, pese a que ello supone un fuerte estigma cultural e institucional. Las mujeres a favor del parto en casa consideran que esta debe ser una experiencia holística, espiritual, que desean alejar del punto de vista mecánico que tiene una perspectiva objetualizada del cuerpo.

La tercera parte se ocupa de la dimensión política de las geografías reproductivas: la migración por motivo de maternidad de China a Hong Kong, las campañas pro natalistas de carácter nacionalista en Serbia y las conexiones entre la situación medioambiental y la salud maternal e infantil en Ghana. Tras convertirse Hong Kong en un Región Administrativa Especial, algunas familias chinas vieron mejores condiciones sanitarias en la región y emprendieron proyectos migratorios. Aunque, aparentemente, Hong Kong podría haber visto esta inmigración de forma positiva y una solución al envejecimiento de su población, en 2013 se prohibió la entrada de mujeres chinas embarazadas a la región, tras una década de vigilancia a las embarazadas con procedencia de China y una reducción paulatina de los permisos de entrada a Hong Kong.

Feminismo/s 34, diciembre 2019, pp. 367-374 
Durante todo ese periodo, los grupos sociales y políticos a favor de limitar las posibilidades de migración por maternidad, construyeron diversos relatos que apuntaban a una supuesta falta de plazas hospitalarias para atender los partos, hasta que, finalmente se hizo evidente que en la oposición a esta inmigración había un claro subtexto biopolítico. El objetivo principal consistía en fortificar Hong Kong para impedir la llegada de bebés no considerados apropiados, estimados, como menciona Kaiser, alienígenas con potencial invasor que ponían en riesgo la construcción de una nación con un proyecto nacionalista y con una fuerte oposición a China. Este capítulo de Robert Kaiser ofrece un muy bien documentado caso en el que desde el gobierno de una nación se dictan normas específicas para las mujeres y se produce un efecto permanente de vigilancia sobre sus cuerpos, con la finalidad de mantener control sobre la población y alimentar un proyecto político basado en la diferencia.

Carl T. Dahlman escribe en relación a la campaña pro natalista lanzada por el Gobierno de Serbia en 2018. Partiendo de la geopolítica de la reproducción, muestra un ejemplo de construcción de nacionalismo contemporáneo, lo que entiende como una práctica biopolítica, que se ejerce bajo la idea de que las mujeres son simultáneamente propiedad y reproducción, al mismo tiempo que la natalidad se promueve con el objetivo de asegurar la presencia en un territorio, es decir, en la lógica patriarcal de la competición por el control y la expansión de los territorios. Como expone el autor, los estudios sobre nacionalismo han hablado tradicionalmente de las prácticas masculinas de conquista y articulación de la nación, obviando el papel de las mujeres en la reproducción, así como en el desarrollo y en el sustento de la vida. De ahí que el enfoque biopolítico se haya esforzado por orientar la comprensión de la ideología nacionalista desde su dimensión de género y que resulte fundamental para entender el desarrollo del nacionalismo en Serbia. Pese a que las mujeres durante largo tiempo no fueron inscritas en los censos de población -las primeras aparecen a partir de los censos de 1862-, sí que fueron tenidas en cuenta como instrumento para el nacionalismo. La geopolítica reproductiva llegó a ser tan importante en el conflicto de la antigua Yugoslavia que, una vez disuelta como tal, se produjeron más guerras en las que el objetivo demográfico era el principal. Siendo así, el ejército serbio utilizó los campos de violación no sólo como un arma de castigo durante la guerra, sino como 
Reseña de: Marcia R. England, Maria Fannin y Helen Hazen (eds.). Reproductive Geographies. Bodies, Places and Politics. Oxon y New York: Routledge, 2019. 242 pp.

ISBN : 978-0815386193

un mecanismo para embarazar forzosamente a las mujeres musulmanas y católicas con la finalidad de construir la nación serbia.

Rishworth y Dixon presentan un caso de estudio localizado en el área rural del norte de Ghana, en el que se evidencia que una situación de vulnerabilidad ambiental incide directamente en la salud maternal e infantil, que se agrava junto a otros factores, entre los cuales encontramos la inseguridad alimentaria y el empobrecimiento estructural. Para ello, emplean un marco teórico sobre Ecología Política Feminista de la Salud, campo que estudia las formas en las que las situaciones ambientales articulan las posibilidades de salud y bienestar de las personas en conexión con las estructuras creadas por el género y, específicamente, los efectos negativos que la devastación ambiental ocasiona en ambos. Las autoras describen el contexto geográfico del área de estudio, el noroeste de Ghana, una de las regiones más empobrecidas del país, con tasas de pobreza dos y tres veces superiores a la media, una situación de ruina ocasionada ya en los tiempos coloniales. Con un clima marcado por la aridez, que no permite una producción agrícola suficiente y, siendo la mayor parte de la población campesina, los nutrientes ingeridos por las mujeres son muy bajos, lo que probablemente explique los altísimos niveles de anemia de los y las bebés de 1 y 2 años de edad. Pese a que en las últimas décadas se ha implementado en Ghana un sistema de salud que da cobertura gratuita a las mujeres embarazadas y a los y las menores de tres meses, las dificultades ocasionadas por las largas distancias del medio rural a los centros de atención sanitaria, así como las cargas de cuidados familiares que asumen las mujeres y la inseguridad de recursos básicos, como el acceso al agua, impiden en muchos casos que éstas puedan obtener atención sanitaria.

El estudio emplea una metodología cualitativa, en la que se realizó un extenso trabajo de campo con entrevistas grupales e individuales, donde se exploraba el acceso a los sistemas de salud y cuidados maternales. Los datos recopilados y la muestra de testimonios son finalmente agrupados en tres ideas: la primera, la salud maternal está configurada por la relación sistémica sociedad y ecología; la segunda, es preciso considerar que la salud maternal va más allá del ámbito reproductivo, se encuentra afectada directamente por todo el contexto de salud; la tercera idea, hay una reproducción intergeneracional de las desigualdades. Las autoras consideran que haber empleado el marco teórico mencionado les ha ayudado a extraer información en profundidad,

Feminismo/s 34, diciembre 2019, pp. 367-374 
así como a entender la dimensión holística de la salud, interconectada con los factores sociales, ambientales y políticos, no sólo con el acceso a la misma.

Como conclusión, las editoras del recopilatorio, Marcia R. England, Maria Fannin y Helen Hazen, demuestran que las geografías reproductivas están articuladas por una lógica espacial intrínseca a la reproducción humana y, en concreto, en los ámbitos de la fertilidad, el embarazo y el parto. Por un lado, se constata que los aspectos sociales, culturales y políticos que envuelven a todo lo reproductivo se encarnan en los cuerpos y, en particular, en los de las mujeres, por lo que se han presentado ejemplos de la importancia que adquiere la escala corporal en las indagaciones geográficas. Por otro lado, se evidencia que los desarrollos tecnológicos involucrados en la reproducción actual, han hecho que el factor de la movilidad en todos los bio-materiales implicados, así como los agentes y las personas, hayan llegado a niveles nunca vistos anteriormente. Finalmente, se desprende el grado de politización que contempla todo aquello vinculado a la reproducción humana, sus aspectos biopolíticos y geopolíticos. 